\title{
Discovery and Optimization of Macrocyclic Quinoxaline-pyrrolo- dihydropiperidinones as Potent Pim-1/2 Kinase Inhibitors
}

Victor J. Cee,* Frank Chavez, Jr., Bradley Herberich, Brian A. Lanman, Liping H. Pettus, Anthony B. Reed, Bin Wu, Ryan P. Wurz, Kristin L. Andrews, Jie Chen, Dean Hickman, Jimmy Laszlo, III, Matthew R. Lee, Nadia Guerrero, Bethany K. Mattson, Yen Nguyen, Christopher Mohr, Karen Rex, Christine E. Sastri, Paul Wang, Qiong Wu, Tian $\mathrm{Wu}$, Yang Xu, Yihong Zhou, Jeffrey T. Winston, J. Russell Lipford, Andrew S. Tasker, and Hui-Ling Wang

Amgen Inc., One Amgen Center Drive, Thousand Oaks, California 91320-1799, United States

\section{Supporting Information}

ABSTRACT: The identification of Pim-1/2 kinase overexpression in B-cell malignancies suggests that Pim kinase inhibitors will have utility in the treatment of lymphoma, leukemia, and multiple myeloma. Starting from a moderately potent quinoxalinedihydropyrrolopiperidinone lead, we recognized the potential for macrocyclization and developed a series of 13-membered macrocycles. The structure-activity relationships of the macrocyclic linker were systematically explored, leading to the identification of $9 c$ as a potent, subnanomolar inhibitor of Pim-1 and -2. This molecule also potently inhibited Pim kinase activity in KMS-12-BM, a multiple myeloma cell line with relatively high endogenous levels of Pim-1/2, both in vitro $\left(\mathrm{pBAD} \mathrm{IC} \mathrm{I}_{50}=25 \mathrm{nM}\right)$ and in vivo $\left(\mathrm{pBAD} \mathrm{EC} \mathrm{E}_{50}=30 \mathrm{nM}\right.$, unbound), and a $100 \mathrm{mg} / \mathrm{kg}$ daily dose was found to completely arrest the growth of KMS-12-BM xenografts in mice.

KEYWORDS: Pim kinase inhibitor, multiple myeloma, KMS-12-BM, macrocycle

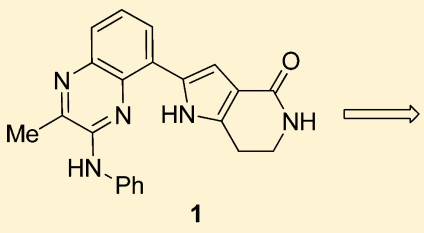

Pim-1/2 IC $50=3 / 2 \mathrm{nM}$ KMS-12 pBAD IC $50=184 \mathrm{nM}$

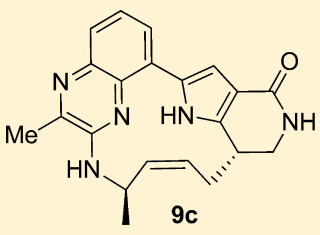

Pim- $1 / 2 \mathrm{IC}_{50}=0.3 / 0.5 \mathrm{nM}$ KMS-12 pBAD IC ${ }_{50}=25 \mathrm{nM}$
$\mathrm{P}$ im-1, -2 , and -3 are highly homologous and constitutively active serine/threonine kinases belonging to the CAMK (calmodulin dependent kinase) family. ${ }^{1}$ The three Pim isoforms phosphorylate a diverse group of proteins with known roles in proliferation, survival, apoptosis, and differentiation. The identification of oncogene-driven aberrant Pim kinase overexpression in subsets of B-cell malignancies ${ }^{2}$ including lymphomas, leukemias, and multiple myeloma, as well as in subsets of solid tumors, ${ }^{3}$ has led to intense efforts to identify small molecule Pim kinase inhibitors. ${ }^{4}$ Because Pim-1 and Pim-2 overexpression are commonly found in B-cell malignancies and because of the overlapping and compensatory nature of Pim-1 and Pim-2, we believe dual Pim-1/2 kinase inhibitors are likely to provide the most broad and durable clinical benefit in the treatment of B-cell malignancies. It is now widely recognized that cellular inhibition of Pim-2 kinase is a significant challenge, due in part to the low $K_{\mathrm{m}}$ of Pim-2 kinase for adenosine triphosphate (ATP), and very few Pim inhibitors have been reported to achieve submicromolar $\mathrm{IC}_{50}$ values in Pim- 2 overexpressing cell lines. ${ }^{5}$ Reported herein is the discovery and optimization of a class of macrocyclic Pim-1/2 kinase inhibitors with double-digit nanomolar activity in KMS-12-BM, a multiple myeloma cell line with relatively high endogenous levels of Pim-1/2.

Screening of kinase inhibitors from prior kinase programs identified a naphthyridine pyrrolodihydropiperidinone as a potent Pim-1/2 kinase inhibitor that exhibited poor selectivity against many kinase off-targets (Figure 1). This screening hit is \section{(1)}


favorable interaction of the 4-pyridyl nitrogen with the backbone hydrogen bond donor presented by most kinase hinge residues. We found that replacement of the naphthyridine with a methylquinoxaline (1) resulted in similar Pim-1/2 potency and improved selectivity against kinase off-targets. ${ }^{10} \mathrm{Pim}-1 / 2$ are able to accommodate both the naphthyridine and quinoxaline cores because the hinge region of the Pim kinases contains a proline residue and therefore lacks the canonical hydrogen-bond donor of all other kinases. In an effort to diversify the aniline substituent, molecules containing $N$-alkyl groups were found to be similarly potent (Figure 1, 2-3). Consideration of the overall shape of these $N$-alkyl molecules led to the hypothesis that the linkage of the $N$-alkyl group and the pyrrolodihydropiperidinone to form a macrocycle would be feasible, and molecular modeling established that a total of five atoms exhibited the minimum necessary length to bridge the quinoxaline and dihydropiperidinone without introducing significant conformational strain (Figure 1, model). We speculated that macrocyclization could result in improved potency due to stabilization of the bound conformation $^{11-13}$ and recognized that the macrocyclic linker itself, or substituents projecting from it, may interact with the protein, specifically P-loop residues Leu-44, Gly-45, and the side chain of Phe-49, more favorably than nonmacrocycles such as 2 and 3.

Ring-closing olefin metathesis ${ }^{14}$ proved to be a reliable strategy for installing the 13-membered macrocycle although in some cases an $\mathrm{SN}_{\mathrm{Ar}}$ macrocyclization was necessary. The olefin resulting from ring-closing metathesis could be reduced via catalytic hydrogenation to provide additional molecules with a saturated bridge. The biological data for a simple set of macrocyclic compounds differing in the macrocyclic bridge and configuration at $\mathrm{C} 9(\mathbf{8}-\mathbf{1 0}, \mathbf{a}-\mathbf{b})$ is presented in Table 1 . For the evaluation of compounds, our program relied on the Pim substrate $\mathrm{Bcl}-2$-associated death promoter (BAD), a proapoptotic $\mathrm{BH} 3$ family member that is inactivated by phosphorylation at Ser-112. A cell-free kinase assay with recombinant Pim-1 and Pim-2 was used to assess the ability of test compounds to inhibit Pim phosphorylation of a short sequence of $\mathrm{BAD}$, and a cellular assay constructed with KMS-12-BM, a multiple myeloma cell line with relatively high endogenous levels of Pim-1/2, was used to assess the ability of test compounds to inhibit Pim phosphorylation of Ser-112 of the full-length $\mathrm{BAD}$ protein. Relative to the initial lead molecules 1-3 (Figure 1), the macrocycles show comparable or improved potency for Pim-1 and Pim-2 enzyme inhibition, with the 9-(S) stereochemistry associated with improved potency relative to the $9-(R)$ stereochemistry.

Encouraged by the favorable data for the simple macrocycles, we synthesized additional analogues with methyl substitution on the atoms linking the quinoxaline to the dihydropiperidinone, focusing on the 9-(S) stereochemistry (Table 1, 8-10, c-f). Substitution with a methyl group was chosen for two reasons. First, due to the presence of accessible lipophilic space in the Pim protein, especially in the region of the macrocyclic linker proximal to the amino group, we believed additional potency could be gained by addition of a small hydrophobe. Second, the initial macrocycles exhibited poor oral bioavailability $(\% F$ in rat for $8 \mathrm{a}, 9 \mathrm{a}$, and $10 \mathrm{a}$ was 2,11 , and 16 , respectively) believed to be due largely to poor aqueous solubility. The poor aqueous solubility, in turn, was likely due to high crystallinity afforded by the planar nature of the quinoxaline-pyrrole biaryl and the lack of rotatable bonds, and it was hypothesized that substitution might serve to reduce crystallinity and improve aqueous solubility. On the $(E)$-alkene framework, the vinyl-methyl macrocycle $8 \mathbf{e}$
Table 1. Pim-1/2 Activity and Solubility of Macrocycles<smiles>CNc1nc2c(-c3cc4c([nH]3)C(OCPC)CNC4=O)cccc2nc1C</smiles>

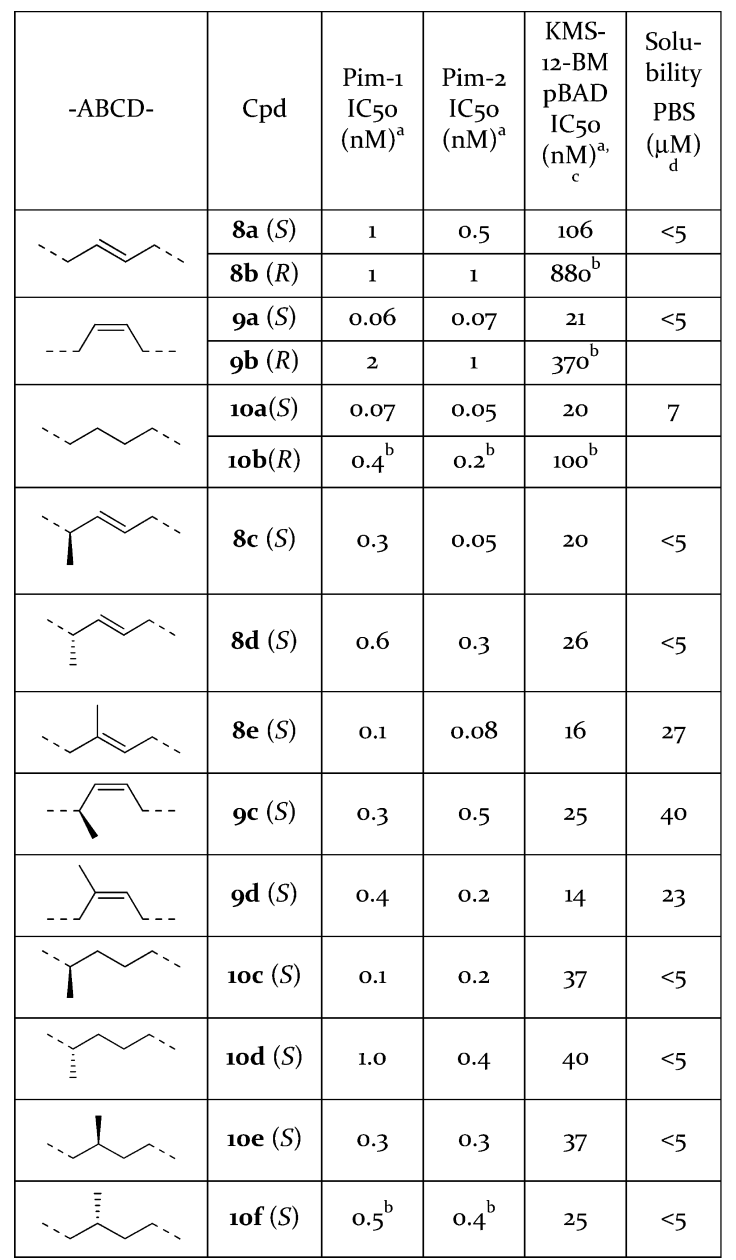

${ }^{a}$ Average of at least 2 determinations; for full statistical information, see the Supporting Information. ${ }^{b}$ One determination. ${ }^{c}$ Assay conducted in the presence of $20 \%$ FBS. ${ }^{d}$ Aqueous equilibrium solubility determined by HPLC; PBS = phosphate-buffered saline.

showed considerable improvement in both potency and solubility, relative to the parent $8 \mathbf{a}$. On the $(Z)$-alkene framework, both allylic substitution (9c) and vinyl substitution (9d) provided molecules with excellent potency and improved solubility. It was not possible to prepare the analogue of $9 \mathrm{c}$ with an epimeric allylic stereocenter via the olefin metathesis route, likely due to $A_{1,3}$-strain and the unique constraints of the macrocycle. While methyl-substituted analogues $(\mathbf{1 0 c}-\mathbf{f})$ of the saturated macrocycle 10a showed good enzymatic and cellular potency, the solubility was uniformly poor.

The X-ray structure of $9 \mathrm{c}$ bound to Pim-1 was obtained and is presented in Figure 2. The presence of a proline (Pro-123) residue in the ATP-binding "hinge" of the Pim kinases results in the absence of the canonical backbone $\mathrm{NH}$ found in other kinases, and this uniquely accommodates the $\mathrm{C}-\mathrm{H}$ at $\mathrm{C}_{19}$ of the quinoxaline. The amino group at $\mathrm{C}_{15}$ of the quinoxaline is $6.0 \AA$ from the $\mathrm{NH}$ of Asp-128, and two water molecules are resolved in 

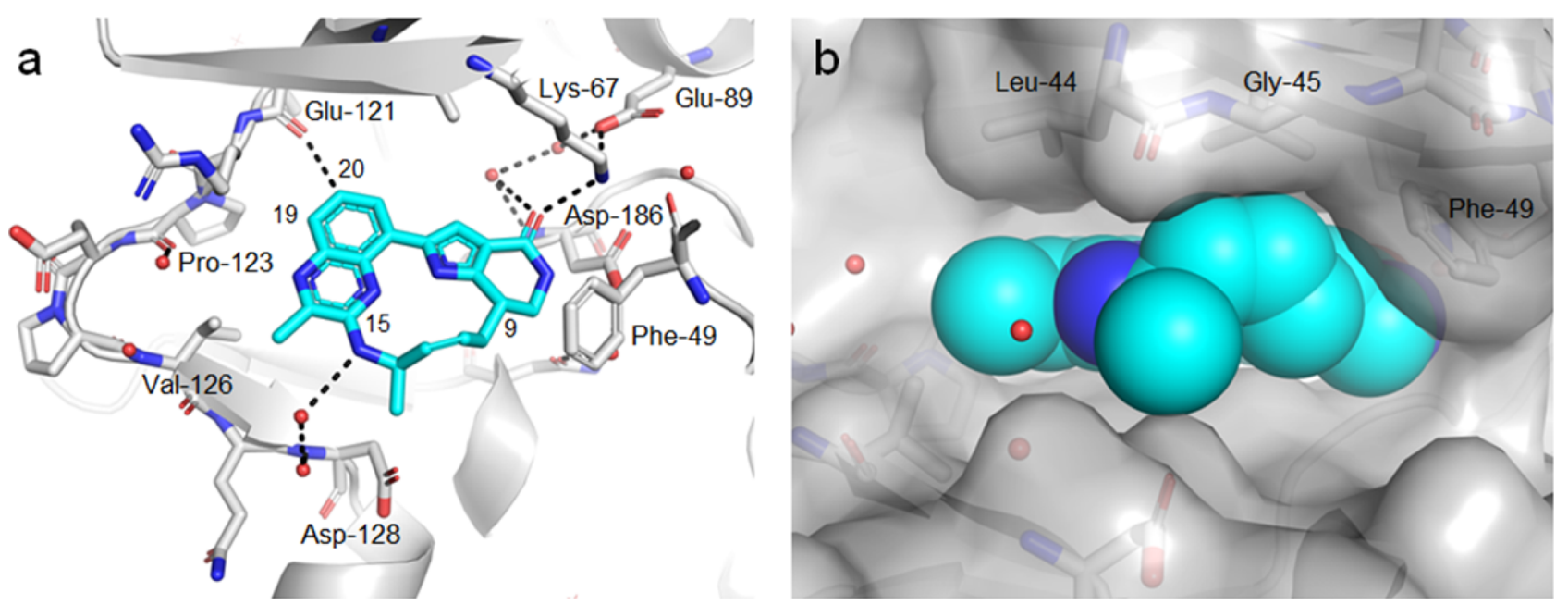

Figure 2. X-ray structure of 9c/Pim-1 (PDB: 5EOL). (a) Compound 9c occupies the ATP-binding site; hydrogen bond contacts are shown with dashed lines; the top of the ATP-binding pocket is omitted for clarity. (b) CPK (Corey-Pauling-Koltun) rendering of $9 \mathrm{c}$ illustrating that the macrocyclic linker forms a complementary hydrophobic surface to Leu-44, Gly-45, and Phe-49.

this space, consistent with a bridged hydrogen-bonding interaction. Another feature of this series is that $\mathrm{C}_{20}$ of the quinoxaline packs closely against the $\mathrm{C}=\mathrm{O}$ of Glu-121 (3.1 $\AA$ ). The carbonyl of the dihydropiperidinone engages in a direct hydrogen bonding interaction with the Lys-67 side chain $(\mathrm{C}=\mathrm{O}$ to $\mathrm{N}$ distance $2.7 \AA$ ) and also forms a water-bridged hydrogen bond to the backbone $\mathrm{NH}$ of Asp-186. The dihydropiperidinone $\mathrm{NH}$ is closely packed against the Asp-186 side chain ( $\mathrm{N}$ to $\mathrm{O}$ distance $3.0 \AA$ ). The $(S)$-configuration at $\mathrm{C}_{9}$ is compatible with the Phe-49 side chain position, which is often observed in Pim-1 structures to be folded under the glycine-rich loop. The macrocyclic linkage connecting the quinoxaline and dihydropyrrolopiperidinone provides a continuous hydrophobic surface, which forms extensive contacts with the P-loop residues Leu-44, Gly-45, and the side chain of Phe-49 (Figure 2b). These interactions may contribute to the improved potency of the macrocyclic series over the related nonmacrocyclic compounds 2 and 3.

The kinase selectivity profile of $9 \mathrm{c}$ was determined in a panel containing 392 nonmutant kinases (scanMAX KINOMEscan, DiscoveRx) at a compound concentration of $1 \mu \mathrm{M}$, and the $S(10)$ and $S(1)$ selectivity scores, representing the fraction of tested kinases with percent-of-control (POC) values $<10$ and $<1 \%$ were determined to be 0.048 and 0.003 , respectively. ${ }^{15}$ Nineteen kinases including Pim- $1 / 2 / 3$ exhibited POC values of less than $10 \%$, with possible off-targets being six members of the Casein kinase family, two members each of the CLK, DYRK, and HIPK families, as well as MYLK4, MAPK15, haspin, and YSK4. These kinases are, to the best of our knowledge, not known to contribute to $\mathrm{BAD}$ phosphorylation. The alpha isoforms of Casein kinase I $\left(\mathrm{CK} 1, C_{\text {CNN } 1)^{16}}\right.$ and II $\left(\mathrm{CK} 2, \mathrm{CSNK}_{2}\right)^{17}$ have been implicated in contributing to multiple myeloma pathology, although the relevance of CK1 and CK2 in the setting of Pim overexpression is not known. Therefore, we believe off-target kinase inhibition to be a limited risk in the interpretation of the impact of $9 \mathrm{c}$ on BAD phosphorylation, but activity on $\mathrm{CK} 1 \alpha$ / CK2 $\alpha$ may impact the viability of KMS-12-BM.

Pharmacokinetic profiles and calculated physicochemical properties of macrocycles possessing good potency and reasonable aqueous solubility $(\mathbf{8 e}, \mathbf{9 c}$, and $\mathbf{9 d}$ ) are presented in Table 2. In general, these molecules exhibited moderate microsomal stability, high plasma protein binding, and good
Table 2. Physicochemical and Pharmacokinetic Properties of Key Macrocycles

\begin{tabular}{|c|c|c|c|}
\hline compd & $8 \mathrm{e}$ & $9 c$ & 9d \\
\hline CLogP/PSA $\left(\AA^{2}\right)^{a}$ & $3.7 / 78$ & $3.7 / 78$ & $3.7 / 78$ \\
\hline RLM \% $\mathrm{TO}^{b}$ & 45 & 39 & 42 \\
\hline HLM $\% \mathrm{TO}^{b}$ & 45 & 24 & 17 \\
\hline Rat PPB $\left(f_{u}\right)^{c}$ & 0.0071 & 0.0070 & 0.016 \\
\hline LLC-PK1 $\mathrm{P}_{\text {app }}(\mu \mathrm{cm} / \mathrm{s})^{d}$ & 33 & 29 & 40 \\
\hline Rat iv CL $(\mathrm{L} / \mathrm{h} / \mathrm{kg})^{e}$ & 2.4 & 0.47 & 0.95 \\
\hline $\mathrm{V}_{\mathrm{ss}}(\mathrm{L} / \mathrm{kg})$ & 3.1 & 1.5 & 1.8 \\
\hline$t_{1 / 2}(\mathrm{~h})$ & 2.8 & 4.0 & 6.1 \\
\hline Rat po $\% \mathrm{~F}^{f}$ & $35^{g}$ & $48^{h}$ & $17^{i}$ \\
\hline
\end{tabular}

${ }^{a}$ Calculated using Chemdraw 12.0.3 (PerkinElmer). ${ }^{b}$ Percent turnover (\%TO) of $1 \mu \mathrm{M}$ compound after $30 \mathrm{~min}$ incubation with liver microsomes $(0.25 \mathrm{mg} / \mathrm{mL}) .{ }^{c}$ Plasma protein binding determined by rapid equilibrium dialysis with $5 \mu \mathrm{M}$ compound. ${ }^{d}$ Average of $\mathrm{A}-\mathrm{B}$ and $\mathrm{B}-\mathrm{A}$ diffusion rates across a single layer of LLC-PK1 cells determined at $5 \mu \mathrm{M}$ compound. ${ }^{e}$ Dosed in male Sprague-Dawley rats $(n=3)$ at 1 $\mathrm{mg} / \mathrm{kg}(\mathbf{8 e})$ and $2 \mathrm{mg} / \mathrm{kg}(9 \mathrm{c}-\mathrm{d})$ in DMSO. ${ }^{f}$ Dosed in male Sprague-Dawley rats $(n=3)$ at $5 \mathrm{mg} / \mathrm{kg}$, in the indicated vehicle selected to maximize compound solubility. ${ }^{g}$ Vehicle $=1 \%$ HPMC, $20 \%$ PEG 400, 79\% water. ${ }^{h}$ Vehicle $=10 \%$ DMAC, $10 \%$ Soluplus, $40 \%$ PEG 400, 40\% water, adjusted to $\mathrm{pH} 2.2$ with methanesulfonic acid. ${ }^{i}$ Vehicle $=10 \%$ Soluplus, 40\% PEG 400, 50\% water, adjusted to $\mathrm{pH} 2.2$ with methanesulfonic acid.

permeability. The in vivo profiles in male Sprague-Dawley rats revealed significant differences in clearance $(0.47$ to $2.4 \mathrm{~L} / \mathrm{h} / \mathrm{kg}$, representing $14-72 \%$ of liver blood flow) and oral bioavailability (17-48\%). Microsomal turnover was not predictive of in vivo clearance, suggesting that conjugation, transporter-mediated processes, or extrahepatic metabolism may have a role in the clearance of these compounds in rat. Compound $9 \mathrm{c}$ was judged to have the best overall profile (lowest clearance and highest oral bioavailability), and this molecule was advanced to in vivo xenograft studies.

As 9c exhibited potent Pim-1/2 kinase activity in the KMS-12$\mathrm{BM}$ cell line (Table $1, \mathrm{IC}_{50}=25 \mathrm{nM}$ ), potent inhibition of KMS$12-\mathrm{BM}$ cell viability in a $72 \mathrm{~h}$ assay (Figure SI-2, $\mathrm{IC}_{50}=151 \mathrm{nM}$ ), and an acceptable pharmacokinetic profile in rodents, further studies were conducted in a mouse xenograft model. The ability of $9 c$ to impact Pim-dependent phosphorylation of BAD (Ser- 

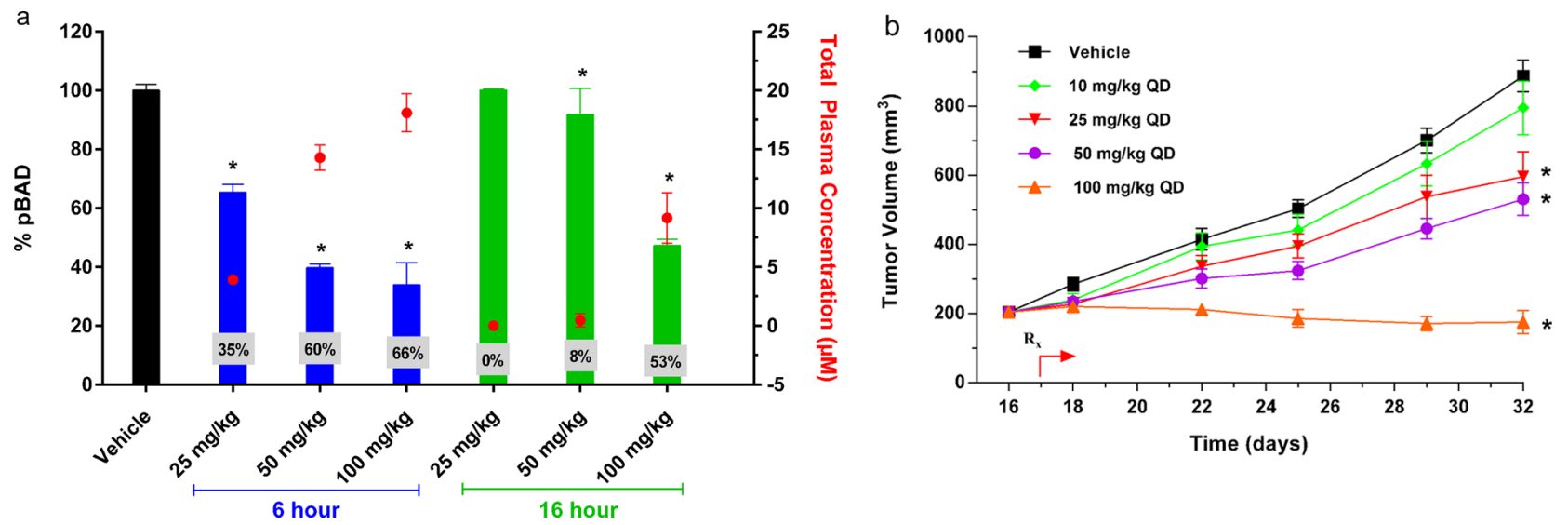

Figure 3. (a) Compound $9 \mathrm{c}(25,50$, or $100 \mathrm{mg} / \mathrm{kg}$ p.o.) is associated with a dose- and concentration-dependent reduction of Ser-112 phosphorylation of BAD in KMS-12-BM xenografts; a single dose of $100 \mathrm{mg} / \mathrm{kg}$ inhibits Pim-dependent BAD phosphorylation at Ser-112 by greater than $50 \%$ for $16 \mathrm{~h}$. Data represent the mean $(n=3) \pm$ standard deviation, with bars corresponding to \%pBAD and the left-hand axis and red circles corresponding to total plasma concentration and the right-hand axis. Statistical significance $(* p<0.05)$ was evaluated by analysis of variance (ANOVA), followed by Dunnet's post hoc. (b) Compound $9 \mathrm{c}(10,25,50$, or $100 \mathrm{mg} / \mathrm{kg}$ p.o.) is associated with a dose-dependent inhibition of KMS-12-BM growth in a xenograft experiment. Data represent the mean $(n=10) \pm$ SEM. Statistical significance $(* p<0.0001)$ was determined by repeated measures analysis of variance (RMANOVA) followed by Dunnet's post hoc.

112) in vivo was determined in $350 \mathrm{~mm}^{3} \mathrm{KMS}-12-\mathrm{BM}$ tumor xenografts in female SCID-beige mice (Figure 3a). In this model, we typically observe a maximum inhibition of $75 \% \mathrm{BAD}$ phosphorylation at Ser-112 for selective Pim kinase inhibitors; the remainder of $\mathrm{BAD}$ phosphorylation is attributed to other kinases, possibly PKB (AKT). ${ }^{18}$ Compound 9c dosed orally at 25,50 , or $100 \mathrm{mg} / \mathrm{kg}$ provided a dose- and concentrationdependent decrease in KMS-12-BM xenograft $\mathrm{pBAD}$ levels, with $100 \mathrm{mg} / \mathrm{kg}$ achieving greater than $50 \%$ inhibition of $\mathrm{pBAD}$ through $16 \mathrm{~h}$ postdose. The $\mathrm{EC}_{50}$ for $\mathrm{pBAD}$ inhibition was determined to be $3.6 \mu \mathrm{M}$ total plasma $9 \mathrm{c}$ by fitting all individual concentration-response data presented in Figure 3a. As the fraction unbound of $9 \mathrm{c}$ in mouse plasma is $0.0084,{ }^{19}$ this corresponds to an unbound plasma concentration of $30 \mathrm{nM}$, in good agreement with the measured in vitro $\mathrm{IC}_{50}$ of $25 \mathrm{nM}$ (Table $1)$. The same KMS-12-BM xenograft model was employed to determine the impact of $9 \mathrm{c}$ on KMS-12-BM tumor growth in vivo (Figure $3 b$ ). Compound 9c dosed orally once daily at 10, 25, 50, or $100 \mathrm{mg} / \mathrm{kg}$ provided a dose-dependent decrease in KMS-12BM tumor volume compared to vehicle treatment, with $100 \mathrm{mg} /$ $\mathrm{kg}$ achieving complete tumor growth inhibition. All doses were well tolerated, with minimal impact on body weight over the course of the study. These data suggest that in vivo exposures above the in vitro $\mathrm{IC}_{50}$ for at least $16 \mathrm{~h}$ with greater than $50 \%$ $\mathrm{pBAD}$ inhibition result in significant tumor growth inhibition.

In conclusion, a series of macrocyclic Pim-1/2 kinase inhibitors was developed from nonmacrocyclic precursors. Some macrocycles exhibited large improvements in potency in both Pim-1 and Pim-2 cell-free enzyme assays as well as in a cellular assay measuring Pim-1/2-dependent phosphorylation of $\mathrm{BAD}$. The improved potency may result from stabilization of the bound conformation as well as additional favorable van der Waals interactions between the macrocyclic linker and Pim protein. The (Z)-configured, allylic-methyl substituted macrocycle 9c was judged to exhibit the best combination of enzyme and cellular potency, solubility, and pharmacokinetics. In a KMS-12BM tumor xenograft model, 9c dosed orally was capable of inhibiting Pim-dependent phosphorylation of $\mathrm{BAD}$ with an $\mathrm{EC}_{50}$ of $3.6 \mu \mathrm{M}$ (30 $\mathrm{nM}$ free unbound 9c), and the highest dose studied $(100 \mathrm{mg} / \mathrm{kg})$ provided greater than $50 \%$ inhibition of
BAD phosphorylation for at least $16 \mathrm{~h}$. A daily oral dose of 100 $\mathrm{mg} / \mathrm{kg} \mathrm{9c}$ was capable of completely inhibiting the growth of KMS-12-BM xenografts in a 16-day efficacy model and was well tolerated. Compound 9c represents the first example of a macrocyclization strategy leading to improved Pim kinase inhibitors, and we have demonstrated that 9c has properties suitable for the in vivo study of Pim kinase inhibition.

\section{ASSOCIATED CONTENT}

\section{S Supporting Information}

The Supporting Information is available free of charge on the ACS Publications website at DOI: 10.1021/acsmedchemlett.5b00403.

Statistical analysis of data presented in Tables 1 and 2. Experimental procedures for the preparation of compounds 8-10 and full characterization. Experimental procedure for crystallography and electron density map of 9c/Pim-1. Description of assays. ScanMAX KINOMEscan panel data for compound 9c. Mouse body weight for the KMS-12-BM xenograft study presented in Figure 3 (PDF)

\section{AUTHOR INFORMATION}

\section{Corresponding Author}

*E-mail: vcee@amgen.com. Phone: 805-313-5500.

\section{Author Contributions}

All authors have given approval to the final version of the manuscript.

\section{Notes}

The authors declare no competing financial interest.

\section{ACKNOWLEDGMENTS}

We thank Wes Barnhart, Kyung Gahm, and Sam Thomas for chiral SFC separation of intermediates and final compounds; Heather Eastwood for high throughput solubility determination; Chris Scardino for ICP (inductively coupled plasma) metal analysis; Ed Lobenhofer for comparative biology and safety science support; and Iain Campuzano for high resolution mass spectrometry. 


\section{ABBREVIATIONS}

$\mathrm{BAD}, \mathrm{Bcl}$-2-associated death promoter; $\mathrm{CL}$, clearance; $\mathrm{CPK}$, Corey-Pauling-Koltun; FBS, fetal bovine serum; HLM, human liver microsome; HPMC, hydroxypropyl methyl cellulose; PKB, protein kinase B; RLM, rat liver microsome; PBS, phosphatebuffered saline; $\mathrm{PPB}$, plasma protein binding; $\mathrm{RCM}$, ring closing metathesis; SFC, supercritical fluid chromatography

\section{REFERENCES}

(1) Nawijn, M. C.; Alendar, A.; Berns, A. For better or for worse: the role of Pim oncogenes in tumorigenesis. Nat. Rev. Cancer 2011, 11, 2333.

(2) Lu, J.; Zavorotinskaya, T.; Dai, Y.; Niu, X.-H.; Castillo, J.; Sim, J.; Yu, J.; Wang, Y.; Langowski, J. L.; Holash, J.; Shannon, K.; Garcia, P. D. Pim2 is required for maintaining multiple myeloma cell growth through modulating TSC2 phosphorylation. Blood 2013, 122, 1610-1620.

(3) Brault, L.; Gasser, C.; Bracher, F.; Huber, K.; Knapp, S.; Schwaller, J. PIM serine/threonine kinases in the pathogenesis and therapy of hematologic malignancies and solid cancers. Haematologica 2010, 95, 1004-1015.

(4) Drygin, D.; Haddach, M.; Pierre, F.; Ryckman, D. M. Potential Use of Selective and Nonselective Pim Kinase Inhibitors for Cancer Therapy. J. Med. Chem. 2012, 55, 8199-8208.

(5) Garcia, P. D.; Langowski, J. L.; Wang, Y.; Chen, M.; Castillo, J.; Fanton, C.; Ison, M.; Zavorotinskaya, T.; Dai, Y.; Lu, J.; Niu, X.-H.; Basham, S.; Chan, J.; Yu, J.; Doyle, M.; Feucht, P.; Warne, R.; Narberes, J.; Tsang, T.; Fritsch, C.; Kauffmann, A.; Pfister, E.; Drueckes, P.; Trappe, J.; Wilson, C.; Han, W.; Lan, J.; Nishiguchi, G.; Lindvall, M.; Bellamacina, C.; Aycinena, J. A.; Zang, R.; Holash, J.; Burger, M. T. PanPIM Kinase Inhibition Provides a Novel Therapy for Treating Hematologic Cancers. Clin. Cancer Res. 2014, 20, 1834-1845.

(6) Ohtsuki, T.; Yawata, Y.; Wada, H.; Sugihara, T.; Mori, M.; Namba, $\mathrm{M}$. Two human myeloma cell lines, amylase-producing KMS-12-PE and amylase-non-producing KMS-12-BM, were established from a patient, having the same chromosome marker, $\mathrm{t}(11 ; 14)(\mathrm{q} 13 ; \mathrm{q} 32)$. Br. J. Haematol. 1989, 73, 199-204.

(7) Anderson, D. R.; Meyers, M. J.; Vernier, W. F.; Mahoney, M. W.; Kurumbail, R. G.; Caspers, N.; Poda, G. I.; Schindler, J. F.; Reitz, D. B.; Mourey, R. J. Pyrrolopyridine inhibitors of mitogen-activated protein kinase-activated protein kinase 2 (MK-2). J. Med. Chem. 2007, 50, 2647-2654.

(8) Vanotti, E.; Amici, R.; Bargiotti, A.; Berthelsen, J.; Bosotti, R.; Ciavolella, A.; Cirla, A.; Cristiani, C.; D’Alessio, R.; Forte, B.; Isacchi, A.; Martina, K.; Menichincheri, M.; Molinari, A.; Montagnoli, A.; Orsini, P.; Pillan, A.; Roletto, F.; Scolaro, A.; Tibolla, M.; Valsasina, B.; Varasi, M.; Volpi, D.; Santocanale, C. Cdc7 kinase inhibitors: Pyrrolopyridinones as Potential Antitumor Agents. 1. Synthesis and Structure-Activity Relationships. J. Med. Chem. 2008, 51, 487-501.

(9) Huang, H.; Acquaviva, L.; Berry, V.; Bregman, H.; Chakka, N.; O'Connor, A.; DiMauro, E. F.; Dovey, J.; Epstein, O.; Grubinska, B.; Goldstein, J.; Gunaydin, H.; Hua, Z.; Huang, X.; Huang, L.; Human, J.; Long, A.; Newcomb, J.; Patel, V. F.; Saffran, D.; Serafino, R.; Schneider, S.; Strathdee, C.; Tang, J.; Turci, S.; White, R.; Yu, V.; Zhao, H.; Wilson, C.; Martin, M. W. Structure-based design of potent and selective CK1 $\gamma$ inhibitors. ACS Med. Chem. Lett. 2012, 3, 1059-1064.

(10) For selectivity comparison of the screening hit and compound $\mathbf{1}$ in a scanMAX KINOMEscan panel, see Figure SI-1 in the Supporting Information.

(11) Giordanetto, F.; Kihlberg, J. Macrocyclic Drugs and Clinical Candidates: What Can Medicinal Chemists Learn from Their Properties? J. Med. Chem. 2014, 57, 278-295.

(12) Villar, E. A.; Beglov, D.; Chennamadhavuni, S.; Porco, J. A., Jr.; Kozakov, D.; Vajda, S.; Whitty, A. How proteins bind macrocycles. Nat. Chem. Biol. 2014, 10, 723-731.

(13) Vendeville, S.; Cummings, M. D. Synthetic macrocycles in smallmolecule drug discovery. Annu. Rep. Med. Chem. 2013, 48, 371-386.
(14) Vougioukalakis, G. C.; Grubbs, R. H. Ruthenium-Based Heterocyclic Carbene-Coordinated Olefin Metathesis Catalysts. Chem. Rev. 2010, 110, 1746-1787.

(15) For more information, see Tables SI-2 and SI-3 in the Supporting Information.

(16) Hu, Y.; Song, W.; Cirstea, D.; Lu, D.; Munshi, N. C.; Anderson, K. C. CSNK1 $\alpha 1$ mediates malignant plasma cell survival. Leukemia 2015, 29, 474-482.

(17) Piazza, F. A.; Ruzzene, M.; Gurrieri, C.; Montini, B.; Bonanni, L.; Chioetto, G.; Di Maira, G.; Barbon, F.; Cabrelle, A.; Zambello, R.; Adami, F.; Trentin, L.; Pinna, L. A.; Semenzato, G. Multiple myeloma cell survival relies on high activity of protein kinase CK2. Blood 2006, 108, 1698-1707.

(18) Amaravadi, R.; Thompson, C. B. The survival kinases Akt and Pim as potential pharmacological targets. J. Clin. Invest. 2005, 115, 26182624.

(19) Determined by ultracentrifugation in mouse plasma (5 $\mu \mathrm{M} 9 \mathrm{c})$ and LC/MS analysis. 